\title{
The Life Project
}

\author{
Camille Baker \\ Brunel University \\ London \\ United Kingdom \\ camille@swampgirl67.net
}

\author{
Fiona French \\ London Metropolitan \\ University \\ London \\ United Kingdom \\ f.french@londonmet.ac.uk
}

\author{
Evan Raskob \\ Openlab Workshops \\ London \\ United Kingdom \\ evan@FLKR.com
}

\author{
Nick Rothwell \\ Cassiel.com \\ London \\ United Kingdom \\ nick@cassiel.com
}

with Andrew Crowe, Giorgio Demarco, Steven Fortune, Gustavo Guerrero, Lori Ho, Simon Katan, Chris Lowell, Manuel Mazzotti, David McLellan, Francesca Perona, Darren Perry, Elvia Vasconcelos and support from SPACE Studios

\begin{abstract}
The Life Project explores issues of psychological projection into technology by diving into the convoluted relationship between practical purpose and emotional attachment, through both the creative act of designing and making robot entities with artificial emotions, and the social act of engaging with them. This process explores the concept of body representation through a multiidentity in virtual and physical blended space. In a lesser sense, it also suggests a future world of collaboration between physical and virtual forms, enabled by new forms of representation in blended worlds.
\end{abstract}

Robots, Avatars, Open Source, Twitter, QR Code, Emergence, Virtual Lifeform, Craft, Design, Workshop.

\section{INTRODUCTION}

The Life Project was originally conceived by Openlab Workshops as a collaborative workshop series for a diverse group of artists, designers, makers and musicians, developed as part of the Permacultures exhibitions at SPACE Studios (SPACE 2012). The aim of the workshops was to explore the boundary between the virtual and the real by examining our complex, mutually dependent relationship with technology. This aim was to be achieved by designing and building an "ecosystem" of small digital Creatures (or robots) that would mutually interact and influence each other, and also interact with human participants who could choose to feed them and/or alter their environmental parameters in meaningful ways.

Inspiration was taken from a variety of sources including generative systems such as Conway's Game of Life as an investigation of emergent behaviour, ecological and environmental concerns, digital pet toys such as Tamagotchi, video games and $\mathrm{Al}$, as well as current research into modeling emotional intelligence systems.

\section{VIRTUAL RELATIONSHIPS}

Most technologists understand that robots are purely mechanical devices, incapable of friendship, inner thoughts, or human emotion. This practical knowledge directly conflicts with our primal human instinct to anthropomorphise and empathise with animate beings, assigning feelings to them that they may or may not have, but that we certainly possess (Nass et al. 1997). For example, silencing a creature's thoughts and emotions is a decision we do not take lightly: studies show that manually powering off a robot while it is actively moving around and making sounds causes emotional conflict in almost all people, regardless of whether or not they understand that the mechanism is, purely, a robot (Turkle 2011, loc 815-816). In a fundamental way, we embody our technological avatars with our own consciousness.

The designing and building workshops forming the core of the project operated according to an "ecological perspective" of art, which Suzi Gablik (1991) explained as:

connect[ing] art to its integrative role in the larger whole and the web of relationships in which art exists, emphasizing community and environment, and giving a deeper account of what art is doing, reformulating its meaning and purpose beyond the gallery system, in order to redress the lack of concern, within the aesthetic model, for issues of context and social responsibility.

Forming a relationship with something or someone is a process that occurs over time. This basic observation drives the focus of the workshops on 
"process, not product." The end result of the workshops is less reliant on an actual, completely realised, physical "Creatures" than the a formative process of social discourse and learning centered around the planning and making them. Through making the Creatures and their world we gradually unpick the complex, recursive relationship we have between the things we make and ourselves, or to paraphrase McLuhan in Understanding Media (1964), how we shape our tools and our tools in turn shape us.

\section{PROJECT DEVELOPMENT}

\subsection{Overview of the First Iteration}

The first iteration of the project started in April 2011 and culminated in a public exhibition in October 2011, at SPACE Studios in Hackney, London (Fig. 1), where the team installed working digital components and displayed important concepts developed over the first phase of the project.

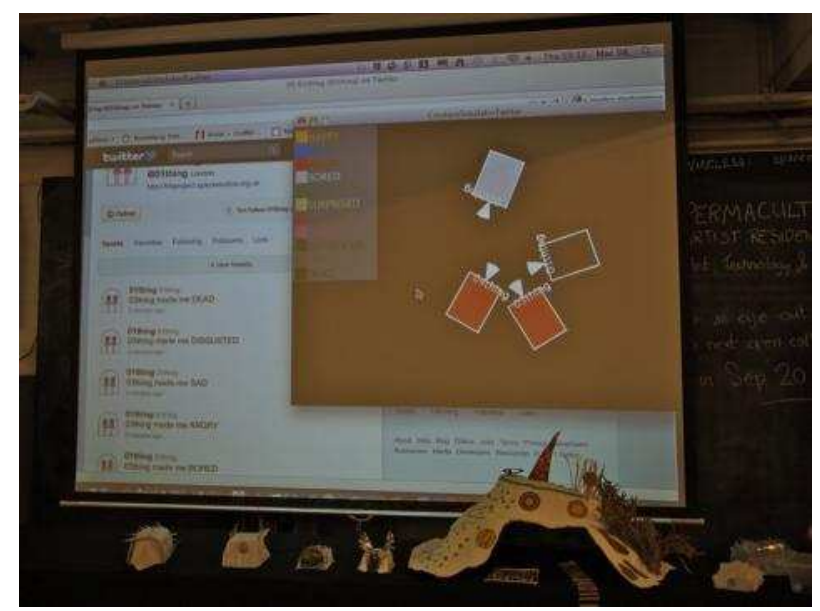

Figure 1: Exhibition in SPACE Studios

Over these seven months, a group of around twenty volunteers came together to respond to the original brief, under the guidance of facilitator Evan Raskob of Openlab Workshops. They met weekly to discuss and debate the project's design and outcomes at first, and later on to take part in learning and building sessions where they both learned and taught digital and craft skills in a collaborative space at SPACE. Team members also met virtually during the week, and blogged about the meetings (Life Project blog 2012) so that members of the public, as well as team members, could engage with the process. The exhibition in October showed the results of their sessions: a series of digital "Creatures" situated in an sculptural, responsive "Environment," along with diagrams explaining the Creatures' $\mathrm{Al}$ and the plan for the finished installation.

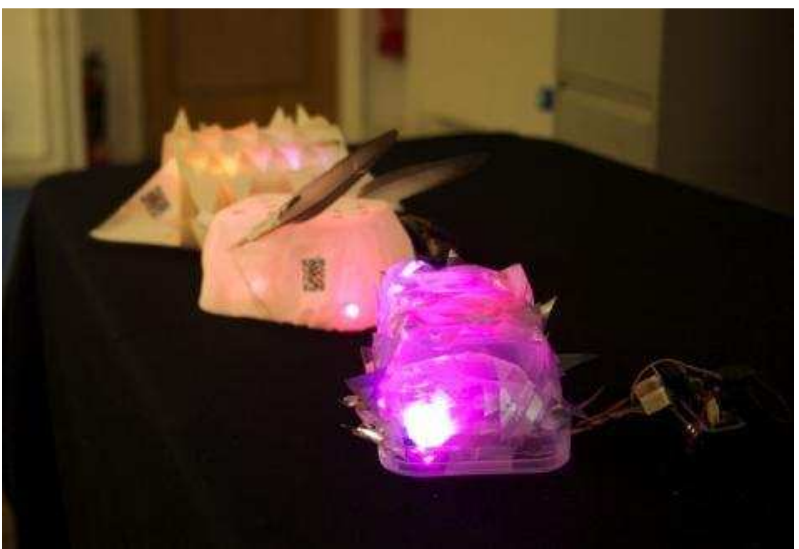

Figure 2: Creatures exchange feelings

Inherent to the Creatures was an emotional $\mathrm{Al}$ system, based on a simplistic model of human emotions (Lee et al. 2008, p.104-113), so they could affect one another (Fig.2) and respond in an appropriate way to human participants.

The Environment was designed to influence the Creatures' emotions and act as a conduit between the outside world (Twitter and other Internet sources) and each Creature's self-contained world in the gallery space.

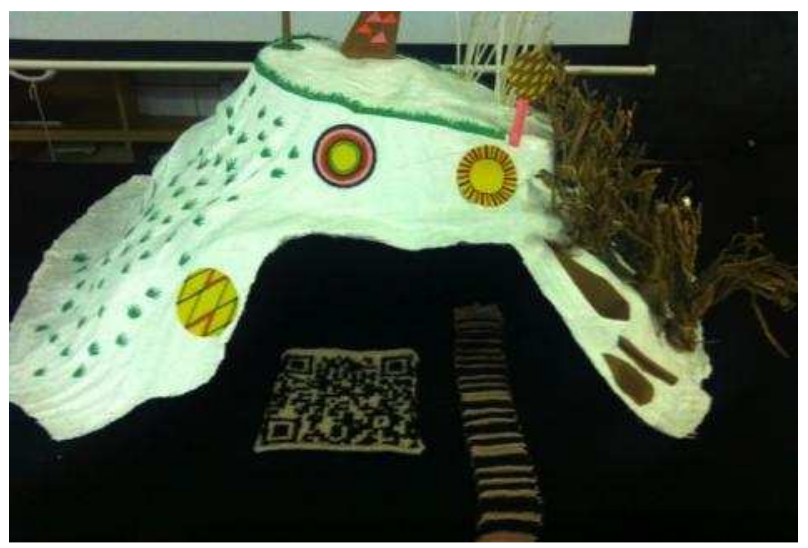

Figure 3: The Happy Cave

Both the Creatures and the Environment were constructed from a system of microprocessors with a variety of $1 / O$ including sensors, lighting, sound, and actuators. Creatures communicated invisibly with one another and with their constructed Environment using wireless radio and infrared pulses.

Areas of the Environment could influence the Creature's emotional states in appropriate ways, such as the "Anti-Social Forest" constantly broadcasting an "anti-social" emotion to the Creatures using infrared communication, and a "Happy Cave" (Fig.3) similarly broadcasting "happiness." 
As the Creatures' emotional $\mathrm{Al}$ and response systems were developed, the team supplied them with their own individual Twitter accounts for sharing their emotions and responding to humans. Additionally, people could feed the Creatures by scanning QR codes attached to them, and alter their moods by repositioning them at specific places in the Environment.

\subsection{Technological Considerations}

The technology platform for the project was driven by the core philosophy of the facilitating organisation, Openlab Workshops (OLW). OLW develops and runs educational workshops across the UK, but mainly in London. Their focus is on teaching people how to use Free/Libre Open Source Software (FLOSS) technology effectively in their own creative practice. This involves explaining copyright and legal issues surrounding free and non-free software, developing practical software and hardware skills, constructing projects using collaborative methods, and examining how technology directly affects the creative practice.

OLW was founded on principles of openness, transparency, collaboration, and sharing and requires all workshops to use as much FLOSS technology as possible to achieve their educational aims. For this project, the team required an easy to use, Open Source hardware platform that was inexpensive to fit the project's small budget, and yet versatile enough to allow the team to experiment with a wide variety of sensors, actuators, and other feedback devices.

The team chose the Arduino platform (Arduino 2012), and the Arduino-derived microcontroller platform called the JeeNode (JeeLabs 2012) because they met most of these requirements. Arduinos are microcontroller experimentation platforms with Open Source hardware designs, running Open Source software, and programmed using an Open Source development application (IDE). Physically, they consist of a programmable microprocessor mounted on a prototyping board with standard connections.

The main benefits of the Arduino platform are its simplified, cross-platform programming system and its large and supportive community. Many learning resources are available online, and a wide variety of manufacturers take advantage of their open standards to provide a wide variety of functional accessories such as motor controllers and wireless communication devices. The main issues with the Arduino were its relatively large size and cost, compared with the size and cost of standalone microcontrollers and basic components. Each
Arduino would have taken up over half of our target cost of $£ 40$ per Creature, if used.

Instead, the team chose the JeeNode. The JeeNode is a cheaper, low-power Arduinocompatible board with a smaller footprint and shortrange wireless radio communication technology built into it. JeeNodes have a variety of inexpensive, useful add-on boards that provide outof-the-box functionality for controlling multiple LEDs, motors, and other $1 / O$ devices. The main benefits of the JeeNode were its lower cost, smaller footprint, and additional cost savings from having a built-in wireless board instead of needing to purchase separate units. The downside is that programming the JeeNodes is more complex due to their software's use of more advanced $\mathrm{C}_{++}$ language features and more efficient but complex communication protocols (often using bit operations). This means more time would be spent on rudimentary software development, debugging, and learning new software skills, rather than on active prototyping and systems design.

For rapidly prototyping design ideas in software, the creative coding platform Processing (Processing 2012) was used. Processing is an Open Source, Java-based platform for quickly sketching out ideas in code. The team used Processing to test out ideas in Artificial intelligence, and to interact with Twitter.

All source code and design documents are licensed as Free Software or Open Source and available online (Pixelpusher on Github 2012).

\subsection{Group Organisation}

At the start of the project, the team was quite large and so work began in smaller teams geared towards specific project development roles: a Design Team, an Embedded Systems Team, a Materials Team, and a Web Team. The Design Team was tasked with developing concepts for Creatures: how they might look, where they would exist, what they might do. The Embedded Systems Team would develop practical digital ideas for building the Creatures: sensors, locomotive systems, communication systems, lighting. The Materials Team would investigate practical building materials for the Creatures and their environment, such as fabrics, latex, and sculptural materials. The Web Team was responsible for the blog, group forum, Twitter, and other modes of web-based public and inter-team communications.

After some activity, we found that an Embedded Systems Team and Design Team were sufficient groupings to cover all design issues and decided not to use a separate Materials Team. 


\subsection{Documentation of the Design Process}

The Design Team looked carefully at the relationship between the Creatures and humans, and between the Creatures and their Environment. From team notes, they first started out simply with the concept of "robots that talk to each other" and moved on to looking at more complex interactions between the robots. They explored behaviours from animal life: feeding, sleeping, procreating, being lonely, loving each other, even boredom. The proposition was that without care, Creatures die; left to themselves, they cooperate with one another; over-stimulated, they would grow apathetic and bored, even to the point of dying.

Using such a small number of states to represent the complexity of this robotic life was inspired in part by Conway's simple cellular automata, in the "Game of Life", Alberto de Campo's digital Creatures project Varia Zoosystematica Profundorum (de Campo et al. 2010) as well as general chaos theory and generative forms in nature such as in sea shells (Meinhardt 1998). Representing reality in a convincing form is something computers fundamentally do with only two states, the binary 1 and 0 . It is the structures and processes encoded in simple state values which create meaning: in this case, the way in which the each Creature's state changes over time and in relation to the states of other Creatures and the Environment.

A theme arose of 'anthropology versus husbandry'; thus taking an ethnographic approach of observing the Creatures from an objective distance, without disturbing them. This was contrasted by the view that we should take a hands-on approach, using directly intentional actions to guide their evolution. A question arose as to whether the team should create Creatures requiring human assistance ("domestic" Creatures), or "wild beasts" existing independently of outside intervention. This choice was viewed as "Captivity" versus "The Wild;" Nature versus Nurture; Ecology or Evolution. "Please don't feed the machine" wrote Elvia in her notes.

The team expressed strong moral and ethical feelings around this topic. Was human intervention in nature damaging by its very nature? Members brought up the terms "purity" and "contamination" to qualify this relationship. The discussion about creating artificial "life" quickly became a proxy for discussing our own fraught relationship between humans and the life around us. Are we humans simply another part of nature, or something intrinsically different? Another discussion, inspired by Internet "memes," centred around the theme of "language as virus," where our language or interaction could infect the Creatures' programming and spread amongst them. Might they contaminate us back in some way?

The team decided that the "cellular" Creatures should have their own behaviour when people were not around, as well as their own language for communicating with one another. There was some debate as to whether this language should be observable, and therefore, potentially understandable by humans, or invisible, or just plain unintelligible. "Robots should communicate with one another foremost, and then how the audience interacts with them can be considered the emergent behaviour of the system" wrote Gustavo.

It was suggested that, even if they were incomprehensible in physical form, the Creatures would use Twitter and possibly other Internet mediums to broadcast out thoughts and desires whenever they felt necessary. In the end, the team decided to use light and sound so that people observing the Creatures could figure out what the robots were communicating. Additionally, Twitter feeds would give a wider human audience a voyeuristic look into the fishbowl-like lives of the Creatures.

The need to make a physical installation eventually focused the discussion on creating a list of functionality and requirements for building the Creatures, which became:

(i.) They transmit emotional states to one another using an "emotional map"

(ii.) They transmit "physical states" to one another, such as DEAD and DYING (these states were eventually combined with the emotional states)

(iii.) They live on a raised surface (a table)

(iv.) They contain speakers inside for communication and feedback

(v.) They are transparent, with embedded LEDs, so we can see what goes on inside

(vi.) They have "eyes" (to transmit and receive)

(vii.) There is an Ethernet connection on one Creature to communicate with the outside world

(viii.) The Creatures feed off "Twitter energy" of followers

(ix.) The installation space should allow for remote viewing, using an overhead camera and microphone

(x.) Human interactions - picking up, moving, reaching IR beam - change emotional states

\subsection{The Environment}

The Creatures, being physical beings at the core, had to exist somewhere. The place could not be an arbitrary anywhere, but had to be a particular 
place, with a clear concept behind it. This Environment also had the responsibility of bridging the gap between the physical world of the Creatures and the virtual world of the Internet.

The Environment was not a passive medium that the Creatures existed on top of, nor was it intended as simply a transparent translator/broadcaster for the Creatures. It was to be an agitator with multiple personalities, acting in the same way as a landscape does when it provokes emotions in humans. Places are never neutral; arguably, they influence us just as much if not more than we influence them. "We shape our buildings; thereafter they shape us," said Winston Churchill (1943).

The team devised a list of key emotional features of the Environment. These features would broadcast emotions to the Creatures and affect their emotional states:

(i.) Antisocial Forest (at Francesca's insistence): a place for Creatures to go and be alone; a forest of solace

(ii.) Surprise Rocks: triggering unexpected changes in the Creatures' emotional states through "surprise"

(iii.) Orgasmatron: a place that makes the Creatures "horny" - homage to Wilheim Reich's Orgone Energy Accumulator (Guardian 2012), as parodied by Woody Allen in the movie Sleeper (1973) (iv.) Happy Cave: a primordial place of happiness

(v.) Social Plain: a large, flat area where many Creatures could be positioned by participants and observed communicating with each other

Other features were necessary, such as a place to put the electronics and wiring. Thus, the "Happy Cave" was born as a cavern in the central plateau, with an Antisocial Forest growing on top of it. The electronics (microprocessor, wireless transmitter, wiring) were designed to sit in the middle of the structure housing these two features, easily accessible via snap-off top under the forest.

At the same time, the Environment listened to broadcasts from the Creatures - hunger, emotional interactions between them - and relayed them to the outside world via Twitter. It also worked in reverse, taking communications via Twitter and relaying them back to individual Creatures. These two processes were referred to as "The Conversation."

\subsection{The Conversation}

The Conversation Flowchart (Fig. 4) described the "conversation" between the outside world (people, Twitter, the Web) and the Creatures. People in the installation space could scan the unique QR code (ThinkMakePlay 2011) attached to every Creature, which triggered the Environment to feed them.
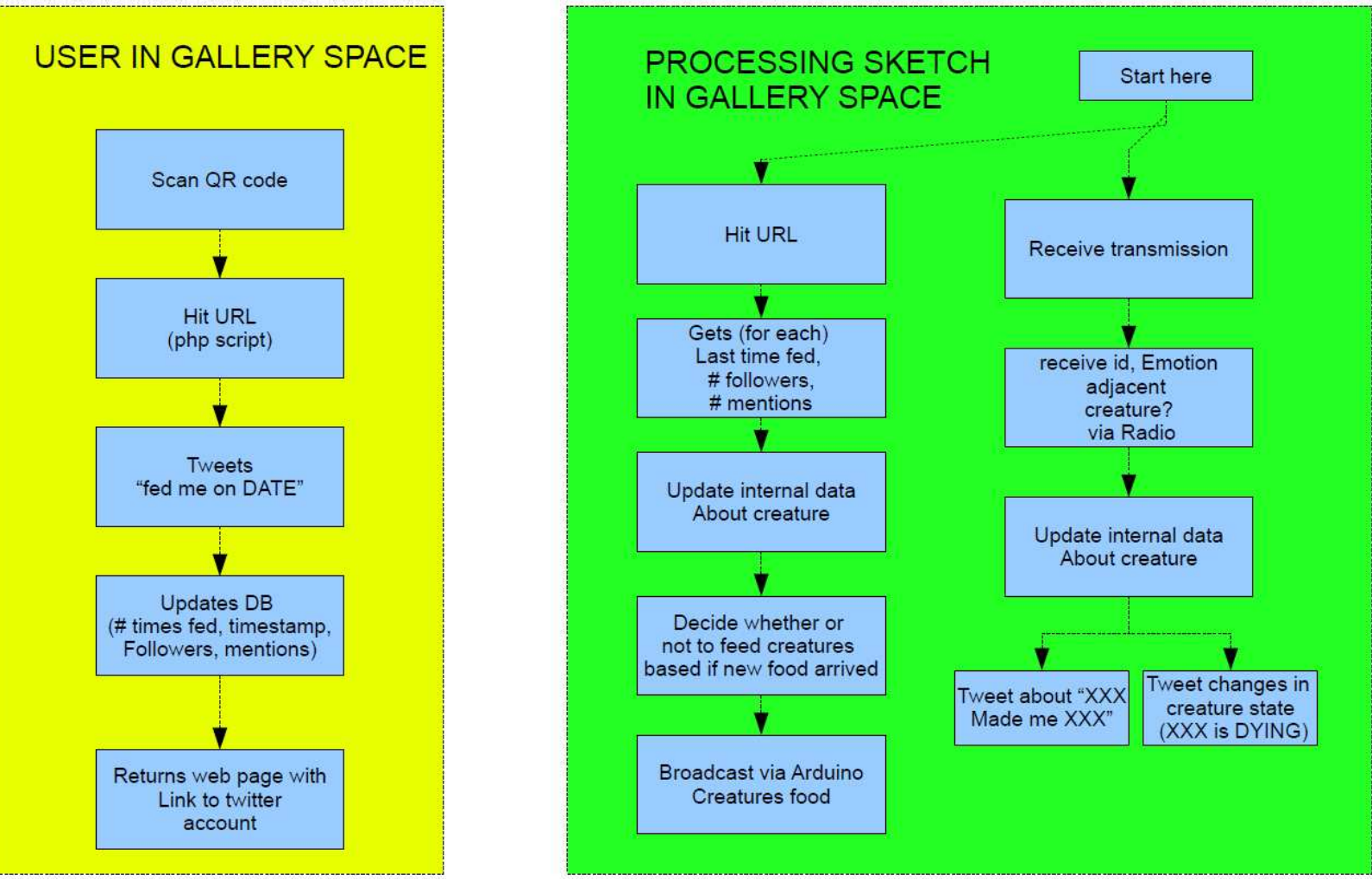

Figure 4: Conversation flowchart 
The left side of the chart above explains this process, which involved decoding the unique QR code into a Web address (URL) that, when accessed in a web browser such as Firefox, ran a PHP script. The script stored the cumulative number of scans of the QR code in a database, then 'tweeted' this number to the Creature's individual Twitter account. Finally, it returned a link to this Creature's twitter account through the web browser for the participant to follow and access the Creature's tweets. This complex QR code tracking process was meant to be invisible to the participant, whose intention was simply to feed the Creature.

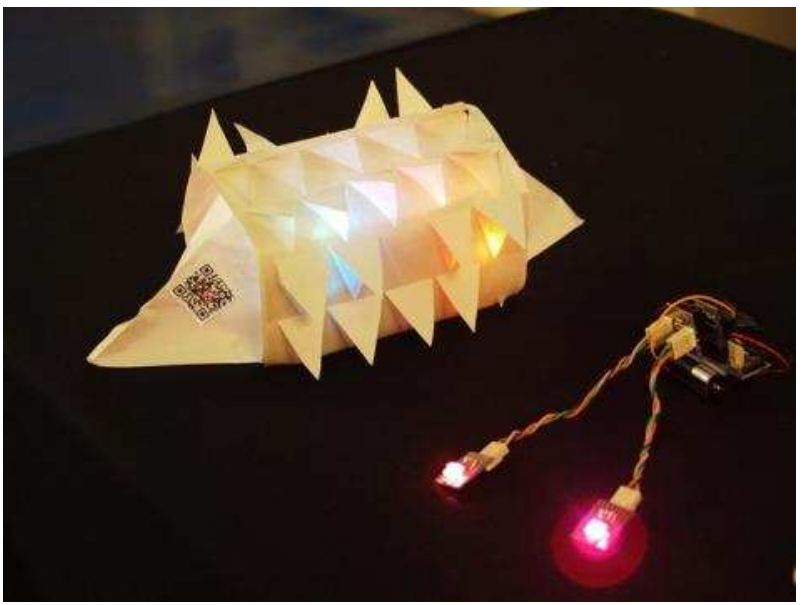

Figure 5: Creature with $Q R$ code beside digital innards

This was only half of the feeding process. The right side of the chart explains how the Environment retrieved the sent information from the web database, and then handled it by "feeding" all the Creatures whose QR codes were scanned. This involved wirelessly broadcasting "feeding" messages targeting specific Creatures by their unique, internal id number.

The Environment also received tattle-tale updates, broadcast from the Creatures wirelessly, telling it about interactions between the Creatures: how one influenced the emotional state of another, such as making it feel "happy" or "sad." This information was fed back to Twitter and the outside world in the form of public tweets, so that observers could follow these interactions.

\subsection{Emotional Intelligence}

These "simple" little Creatures are designed to be more interesting in aggregate than as individuals.

The Creature state flowchart (Fig. 6) described what went on inside the Creatures' "brains."

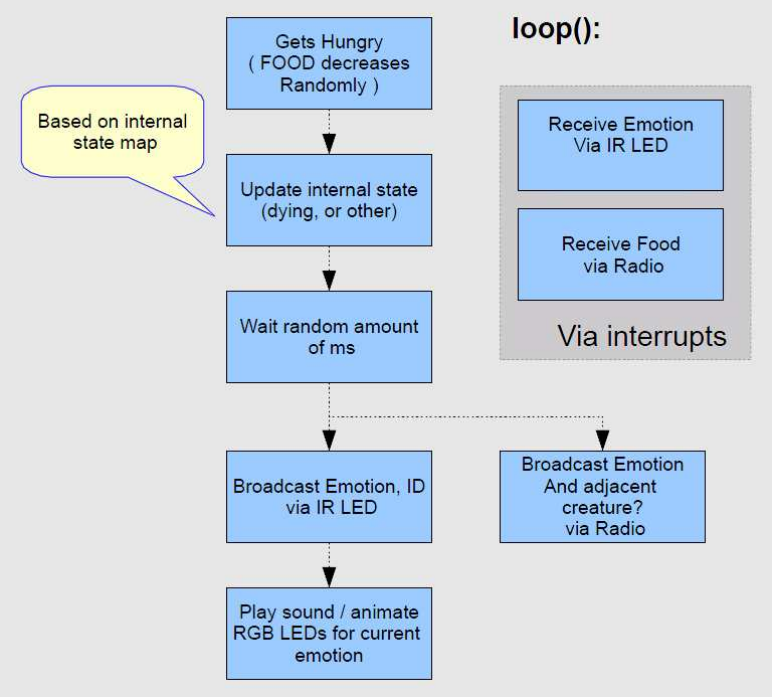

Figure 6: Creature state flowchart

Internally, the Creatures' emotions were constantly in flux, evolving over time based on a large table of rules (their $\mathrm{Al}$ ). Left on their own, they would change emotions in unpredictable ways, based on these rules, which were in turn based on the neuropsychology of how humans change emotion (Lee et al. 2008, pp.104-113). Externally, the Creatures broadcast their emotions invisibly, for other Creatures to pick up. This is like looking at someone else and reading their emotions glancing across the room and seeing an angry man, and becoming confused or fearful. Again, the Creatures have a large table of rules (Pixelpusher on Github 2012) for responding to others' emotions.

While the Creatures are "feeling" a particular emotion, they emit appropriate sounds via a piezo speaker and cycle through colourful animations using dual embedded RGB LEDs (Fig. 5).

The Creatures update their current emotional state, and respond to external emotional broadcasts, via a look-up table in their Arduino code (Pixelpusher on Github 2012) for the external reactions and another for the internal ones (Fig. 7). These tables are essentially lists of probabilities for determining which state a Creature manifests when either time increases (for the internal case) or another Creature confronts it with an emotion (for the external case).

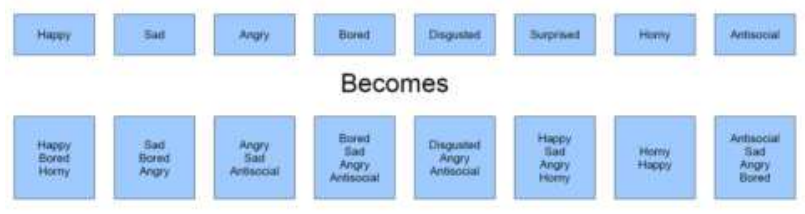

Figure 7: internal emotion changes

\subsection{Manifestation}


The team spent some time considering how best to represent the range of emotional states of the Creatures using a limited number of actuators multi-coloured LEDs, sounds and tweets. The design of the audio and the colour animations came from the team's own artistic ideas, inspired by Dave Griffiths' research into colour-emotion waveforms (Griffiths 2012).

\section{Examples:}

(i.) state: Happy > colour = yellow/green/red > animation = pulsating very brightly.

(ii.) state: Sad $>$ colour $=$ Blue $>$ animation $=$ very slow dimming, then brightening a little, then dim again.

The sounds were synthesised/procedurally generated to miniature speakers on each creature. Tonal variation was inspired by familiar human non-vocal noises associated with particular feelings (culture-specific).

\section{Examples:}

(i.) emulating a "wolf-whistle" to express "horniness",

(ii.) a "chirp" to show "happiness",

(iii.) a low drone for antisocial feelings.

Each creature had its own Twitter account with an application (@LifeButNot) developed using the Twitter API. They are provisionally named "01thing" to "10thing" (after Thing 1 and Thing 2 in Dr Zeuss "Cat in the Hat") and they all follow each other, thereby creating some noise when all switched on and programmed to tweet their feelings. In the last iteration, the messages were minimal - e.g., "Thanks for feeding me at 14.41 .52 - 31/10/2011" and "03thing made me DISGUSTED at $14.40 .48-13 / 10 / 3022 . "$

An early plan to design a one-size-fits-all clone casing for the Creatures (Fig. 8), failed because the team's creativity meant that ideas were wideranging, from the clean simple lines of identical little boxes to bizarre organic tentacled jellyfish. This led to a series of exploratory workshops in August and September 2011, where the design team joined with members of the public to take part in an art project/communal crafting exercise where participants began to personalise the Creatures by creating individual cases using recycled materials.

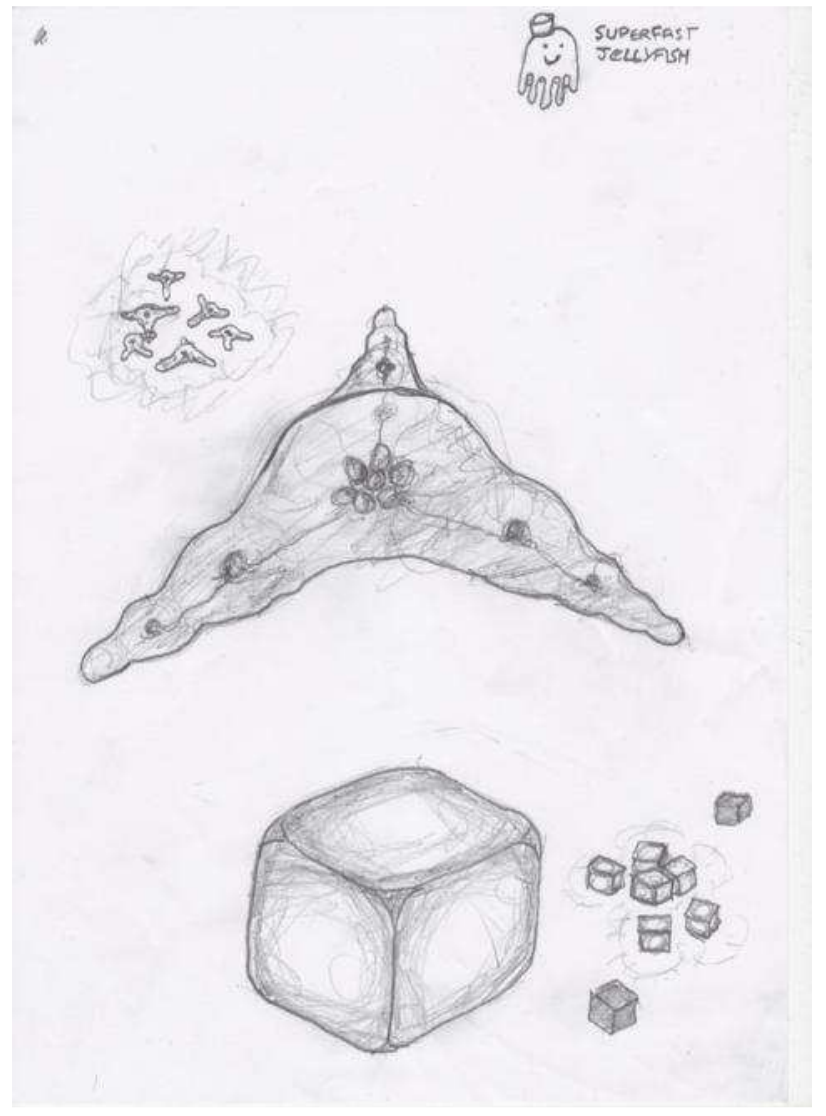

Figure 8: Creature sketch from design workshop

\section{Conclusions}

The Life Project has successfully met its original aim of exploring embodiment and identity through the collaborative process of creating an "ecosystem" of little machines that live, grow, communicate and die with one another, all in the presence of humanity.

The major challenges can be summarised as follows:

(i.) Creative Collaboration: Facilitating a large, diverse group of creative people to work and collaborate effectively together is a daunting task, since The Life Project provided a rare opportunity for designers, crafters, artists, programmers and engineers to develop ideas together on a shared brief, problem-solving and negotiating milestones from concept to finished artefact.

(ii.) Developing an Emotional Intelligence The Life Project explored how software and hardware could be used to represent and communicate changing emotional states. Experiments used software probability tables, animated lights, sounds, 
and tweets - a wide range of outputs, each with their own complexity.

(iii.) Communication and Interaction - The Life Project investigated modes of communication between software and hardware agents and people. Using Infrared LEDs (light emitting diodes) as transmitter/receiver between Creatures and Environment; using Twitter to respond to people via Social Networks; using QR Codes to enable creature husbandry from the public - again with their unique requirements to interconnect with the rest, adding another layer of complexity (and chaos).

(iv.) Look and feel - The Life Project provided an opportunity for community involvement in the later stages of project, which required some of the complexity to be made more readily understandable and accessible for simple engagement and interactivity.

(v.) FLOSS Integration - The FLOSS community and technology was essential to this project. Without the Arduino community, and their companion JeeNodes, the team would have had to purchase expensive proprietary systems or spend much more time developing core technology. The team reciprocated by distributing all code, diagrams, and blogging about the development process.

The team intends to maintain the project as a communal art installation, organizing future workshops and inviting members of the public to contribute their own creative designs to and interact with a slice of digital ecology. The aim is provide future teams the opportunity to study the interaction and the effectiveness of the concepts and intended user interaction, in order to draw conclusions about our complex and interdependent relationship with technology and the "natural" world.

\section{References}

SPACE Studios. http://spacestudios.org.uk (retrieved 2 April 2012).

Life Project blog.

http://lifeproject.spacestudios.org.uk

(retrieved 2 April 2012).

Nass et al. (1997) Computers Are Social Actors: A Review of Current Research. In Human Values and the Design of Computer Technology, Batya Friedman ed. CSLI Productions, Stanford, CA.
Turkle, Sherry (2011) Alone Together: Why We Expect More From Technology and Less From Each Other, Kindle Edition. Basic Books.

Gablik, Suzi (1991) The Reenchantment of Art. Thames and Hudson: New York.

McLuhan, Marshall (1964) Understanding Media. 1st Ed. McGraw Hill, NY.

Tien-Wen Lee, Raymond J. Dolan and Hugo D. Critchley (2008) Controlling Emotional Expression: Behavioral and Neural Correlates of Nonimitative Emotional Responses. Cerebral Cortex, January 2008;18:104-113.

Openlab Workshops. http://openlabworkshops.org (retrieved 2 April 2012).

Arduino. http://arduino.cc

(retrieved 2 April 2012).

JeeLabs. http://jeelabs.com

(retrieved 2 April 2012).

Processing. http://processing.org

(retrieved 2 April 2012).

Pixelpusher on Github.

https://github.com/pixelpusher/EmotionalCreature (retrieved 2 April 2012).

de Campo, Prof. Dr. A., Hannes, H., Wieser R. (2010) Varia Zoosystematica Profundorum. XIII Generative Art Conference (GA2010). Politecnico di Milano University, Italy.

Meinhardt, Hans (1998) The Algorithmic Beauty of Sea Shells (The Virtual Laboratory). 2nd enlarged ed. Edition. Springer.

Wilhelm Reich: the man who invented free love | Books | The Guardian

http://www.guardian.co.uk/books/2011/jul/08/wilhel m-reich-free-love-orgasmatron

(retrieved 2 April 2012).

ThinkMakePlay.

http://www.thinkmakeplay.co.uk/life/

(retrieved 2 April 2012).

Griffiths, Dave, Dave's blog or art and programming.

http://www.pawfal.org/dave/blog/2011/08/colourfulemotions/

(retrieved 2 April 2012). 